\title{
Criminologie
}

\section{Document : Une note... finale : la mort civile}

Volume 18, numéro 1, 1985

L’histoire du contrôle social

URI : https://id.erudit.org/iderudit/017212ar

DOI : https://doi.org/10.7202/017212ar

Aller au sommaire du numéro

Éditeur(s)

Les Presses de l'Université de Montréal

ISSN

0316-0041 (imprimé)

1492-1367 (numérique)

Découvrir la revue

Citer ce document

(1985). Document : Une note... finale : la mort civile. Criminologie, 18(1),

128-129. https://doi.org/10.7202/017212ar d'utilisation que vous pouvez consulter en ligne.

https://apropos.erudit.org/fr/usagers/politique-dutilisation/ 


\section{UNE NOTE... FINALE :}

\section{LA MORT CIVILE}

Sait-on que, lors de son adoption en 1866, le Code civil contenait des dispositions entraînant la mort civile pour les personnes condamnées à certaines peines? Et que l'adoption du Code civil ne visait pas à créer du droit nouveau mais plutôt à codifier le droit existant?

Voici le texte des articles pertinents, qui demeurèrent en vigueur jusqu'en 1906. On pourra les lire en constatant notamment que cet effet "secondaire» de la peine infligée au condamné avait un impact non secondaire sur son conjoint et sa famille.

\section{CHAPITRE DEUXIBME. \\ DE LA PRIYation des nuolts cavils.}

30. Les droits civils so perdent:

1. Dana les cas próvis par loe bies de l'ompire.

2. Pur la mort civilo.

\section{section to. \\ De la mast civils.}

81. Ia mort civille rónulto de la condarnatlon 1 cerLines poines aflictives.

82. La condamnation a la mort natyrolle emporto to mort elvile.

88. Toules autres peines amictiven protpotuellos anportent ausd la mort civile.

84. Loe incapacltés rtaultanit, quent eux personnes quil profecent in roligion catholique, de la profosion roligieuse par l'emisesion de rooux solennela of a perph tritt dens une communauto religieuse reconnue lore de In cenaion du Caneda il'Angloterre ef approuvbo dopuls, redont coumises aux lols quil les ríglalencle cotto bpoque. 
PRCTION It.

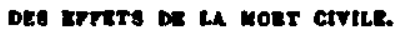

55. La mort civile emporte la perto de tous les biens du condamné, lesquals sont ecquis au souverain \& titro de confscation.

88. La personne morte civilement ne peut.

1. Recueillir of transmettro a titro de nuccession.

2. Bille ne peut disposer de ses biens, ni eccuubrir, moit par ecte eatrovifs ou a cause to mort, soll 1 tilse gratuit ou onéroux: elle ne peut ni contracter ni poseóder; ello pout cependant recevoir des aliments.

3: Bllo ne peut otre nommbe tuteur ni curateur, ai concourir aux opérations qui y sont relatives.

4. Bllo ne peut étro 1émoin dans ancero ecte colennel ou autbentique, nd stre edmiso i portor tomoignege on fustice, ni d servir comme jurt.

5. Blle no peut proceder on junties ai en demendent in on défendant.

6. Elle osk incapable de contrecter un mariage quil produise quelque offet civil.

7. Celui qu'elle avait contracte precodemment ent pour l'avenir dissous quent aux efrets oivils souloment; it subsiste quant au lien.

8. Bon conjoint et ses héritiers peuvent exercer respectivement les droits et actions auxquels se mort naturolto donnerait lieu; sauf les gains de survio auxquols. la mort civile ne donne ouverture que lorsque cet effos: rosulte des termes du contrat de mariage.

a\%. La mort civile est encourue 1 compter do la condemnation judiciaire.

88. Lo pardon, la fiborretion, la remise de le peine ou se commutation on une autre qui n'emporte pas mort civile, rendeat la vis civile au condemnd, mais ands of ot notroactif, a moins d'un acto de perlempat quil comporto cot ellet. 